\title{
Blast-cooling of beef-in-sauce catering meals: numerical results based on a dynamic zero-order model
}

\author{
José A. Rabi ${ }^{\mathrm{a}^{*}}$, Evelyne Derens-Bertheau ${ }^{\mathrm{b}}$, Elisabeth Morelli ${ }^{\mathrm{c}}$, And Isabelle \\ TreZZANi-HaRBELOT ${ }^{\mathrm{d}}$ \\ ${ }^{\text {a }}$ University of São Paulo, Faculty of Animal Science and Food Engineering, Av. Duque de Caxias Norte 225, \\ Pirassununga, SP, 13635-900, Brazil \\ b Irstea, UR GPAN, 1 rue Pierre-Gilles de Gennes, CS 10030, 92761 Antony cedex, France \\ c Agence Nationale de Sécurité Sanitaire de l'Alimentation, de l'Environnement et du Travail, Laboratoire de \\ Sécurité des Aliments, 23 avenue du Général de Gaulle, 94706 Maisons-Alfort, France \\ d AgroParisTech / Institut National de la Recherche Agronomique, UMR1145 Ingénierie Procédés Aliments, \\ F-91300 Massy, France \\ ${ }^{*}$ Corresponding author \\ jrabi@usp.br \\ TEL: +55-19-35654257 \\ FAX: $+55-19-35654284$
}

Received: 7 January 2014; Published online: 18 October 2014

\begin{abstract}
Beef-in-sauce catering meals under blast-cooling have been investigated in a research project which aims at quantitative HACCP (hazard analysis critical control point). In view of its prospective coupling to a predictive microbiology model proposed in the project, zero-order spatial dependence has proved to suitably predict meal temperatures in response to temperature variations in the cooling air. This approach has modelled heat transfer rates via the a priori unknown convective coefficient $h_{c}$ which is allowed to vary due to uncertainty and variability in the actual modus operandi of the chosen case study hospital kitchen. Implemented in MS Excel ${ }^{\circledR}$, the numerical procedure has successfully combined the $4^{\text {th }}$ order Runge-Kutta method, to solve the governing equation, with non-linear optimization, via the built-in Solver, to determine the coefficient $h_{c}$. In this work, the coefficient $h_{c}$ was assessed for 119 distinct recently-cooked meal samples whose temperature-time profiles were recorded in situ after 17 technical visits to the hospital kitchen over a year. The average value and standard deviation results were $h_{c}=12.0 \pm 4.1 \mathrm{~W} \mathrm{~m}^{-2} \mathrm{~K}^{-1}$, whilst the lowest values (associated with the worst cooling scenarios) were about $h_{c} \approx 6.0 \mathrm{~W} \mathrm{~m}^{-2} \mathrm{~K}^{-1}$.
\end{abstract}

Keywords: Convective heat transfer; Thermal food processing; Modelling; Lumped parameter analysis; Food safety 


\section{Abbreviations and nomenclature}

HACCP hazard analysis critical control point

TM-0 thermal model of zero-order dependence on spatial coordinates

TM-1 thermal model of first-order dependence on spatial coordinates

Latin symbols

$A \quad$ area for heat transfer from meal to air $\left(\mathrm{m}^{2}\right)$

$\mathrm{Bi} \quad$ Biot number (dimensionless)

$c \quad$ specific heat capacity of meals $\left(\mathrm{J} \mathrm{kg}^{-1} \mathrm{~K}^{-1}\right)$

$D_{h} \quad$ hydraulic diameter $(\mathrm{m})$

$h_{c} \quad$ convective heat transfer coefficient $\left(\mathrm{W} \mathrm{m} \mathrm{m}^{-2} \mathrm{~K}^{-1}\right)$

$L \quad$ shelf level in the supporting trolley (dimensionless)

$I_{1 / 2} \quad$ half-length separating meal core from horizontal (i.e., top or bottom) edges (m)

$m \quad$ mass of meals in food containers $(\mathrm{kg})$

$N_{\text {laid }} \quad$ number of standardized containers laid in the supporting trolley (dimensionless)

$\mathrm{Nu}_{D} \quad$ Nusselt number based on hydraulic diameter (dimensionless)

Pr Prandtl number (dimensionless)

$\dot{Q} \quad$ heat transfer rate $(\mathrm{W})$

$\operatorname{Re}_{D} \quad$ Reynolds number based on hydraulic diameter (dimensionless)

$T$ temperature $\left(\mathrm{K}\right.$ or $\left.{ }^{\circ} \mathrm{C}\right)$

$t \quad$ time $(\mathrm{s})$

$v_{\text {fluid }} \quad$ reference velocity of cooling air flow $\left(\mathrm{m} \mathrm{s}^{-1}\right)$

Greek symbols

$\beta \quad$ lumped parameter $\left(\mathrm{s}^{-1}\right)$

$\lambda \quad$ thermal conductivity $\left(\mathrm{W} \mathrm{m}^{-1} \mathrm{~K}^{-1}\right)$

$v \quad$ kinematic viscosity $\left(\mathrm{m}^{2} \mathrm{~s}^{-1}\right)$

$\rho \quad$ density $\left(\mathrm{kg} \mathrm{m}^{-3}\right)$

Subscripts and superscripts

air cooling air flowing around a given food container

final shut-down of blast-cooling operation (final instant)

food beef-in-sauce catering meal in a food container at a given position in the trolley

inf below the food container (bottom)

init start-up of blast-cooling operation (initial condition)

meat meat portion of the catering meal

num numerical meal temperature

rec recorded meal temperature

sauce sauce portion of the catering meal

sup above the food container (top)

\section{Introduction}

In food service operations, cooling frequently raises concerns about Clostridium perfringens outbreaks (Steele \& Wright, 2001; Juneja \& Marks, 2002; Kalinowski, Tompkin, Bodnaruk, \& Pruett, 2003; de Jong, Beumer, \& Zwi- etering, 2005). In order to prevent such risks, public health authorities have set specific time-temperature combinations which are achievable via blast-cooling equipment (Doyle, 2002; Crouch \& Golden, 2005). Yet, other combinations can be approved if operators are able to demonstrate that appropriate levels of 
food safety are ensured. Accordingly, modelling and simulation are helpful for risk analysis as well as useful for process improvement and re-engineering (Bellara, McFarlane, Thomas, \& Fryer, 2000; Huang, 2003; Amezquita, Weller, Wang, Thippareddi, \& Burson, 2005; Almonacid, Simpson, \& Teixeira, 2007).

Following such a rationale, a research project on quantitative risk-based HACCP (hazard analysis critical control point), named Quant'HACCP Project, has proposed to model food chain processes on a modular basis, combining predictive microbiology and physical phenomena. Coldchain catering performed at a hospital kitchen was chosen as the case study and the present work focused on beef-in-sauce meals undergoing blast cooling.

As part of the aforesaid project, two dynamic thermal models were tested to predict meal temperatures in response to temperature variations in the cooling air (Rabi, Trezzani-Harbelot, Morelli, \& Guilpart, 2012). While both models relied on a convective coefficient $h_{c}$ to assess heat transfer between hot meals in containers and the cooling air flowing around them, they differed from each other with respect to the spatial dependence of temperatures. In the zero-order model, referred to as TM-0, temperatures could only depend on time $t$ whereas one-dimensional variation was additionally allowed in the firstorder model (TM-1).

In view of its prospective coupling to a predictive microbiology model proposed in another part of the Quant'HACCP project (Jaloustre, Cornu, Morelli, Noel, \& Delignette-Muller, 2011), TM0 was a suitable choice that could be implemented in MS Excel ${ }^{\circledR}$ (Rabi et al., 2012). As claimed in Corradini, Amezquita, Normand, and Peleg (2006), MS Excel ${ }^{\circledR}$ is a general-purpose software, finding widespread use among industrial food microbiologists, when compared to relatively advanced mathematical software like Mathematica ${ }^{\circledR}$, MathCAD $^{\circledR}$ or Maple ${ }^{\circledR}$.

In TM-0 (and also in TM-1), coefficient $h_{c}$ is a priori unknown and allowed to vary due to uncertainty and variability in the usual (nonacademic) modus operandi of the kitchen. Coefficient $h_{c}$ is obtained by best-fitting the numerical meal temperature against the profile recorded in loco along with the temperature-time profile of the cooling air flowing nearby (Rabi et al., 2012). After 17 technical visits to the kitchen over a year, it was possible to apply the numerical procedure to 119 meal samples and this work presents and discusses the average and lowest values of those best-fitting coefficients $h_{c}$.

\section{Blast-Cooling Operation as Case Study}

This section briefly describes the blast-cooling operation habitually carried out at the hospital kitchen taken as the case study. It was arbitrarily chosen from a list of Parisian hospitals performing cold-chain catering at their central kitchens. Filled up with recently-cooked beef-in-sauce meals, food containers are top-sealed with plastic film and laid in a trolley with 20 shelves, as shown in Fig. 1(a). For identification purposes, shelves were numbered upwards from $L=1$ (bottom) to $L=20$ (top). As Figure 1(b) shows, the trolley is placed in a blast-cooling cell, so that a given container is further identified as "front" or "back" whether it is near or opposite the cell door, respectively.

Air currents are induced by four fans vertically lined up in one side of the cell, as shown in Fig. 1(c), so that trolley sides are referred to as "fan" or "wall". As described in (Rabi et al., 2012), warm air is aspired to an evaporator behind the fans while chilled air is blown back to the cell interior through two narrow vertical openings, one at each side of the fans from floor to ceiling.

With standard dimensions (CEN, 1993), two sizes of equal-height rectangular containers were used, namely " $1 / 1$ " (dimensions in $\mathrm{mm}$ : $530 \times$ $325 \times 65$ ) and " $1 / 2$ " (dimensions in $\mathrm{mm}: 265 \times$ $325 \times 65)$. On each trolley shelf, one may place up to 2 containers " $1 / 1$ " or 4 containers " $1 / 2$ ". Each container " $1 / 2$ " counts as 0.5 in the number $N_{\text {laid }}$ of containers laid in the trolley and $N_{\text {laid }}$ was noted to vary from one blast-cooling operation to another.

As the idea was to let food operators pursue their customary (and, by the way, speedy) procedure, no suggestions were given about containers' placement. In other words, no pre-defined pattern was followed so that containers were laid at random in the trolley. A pictorial sketch was pro- 


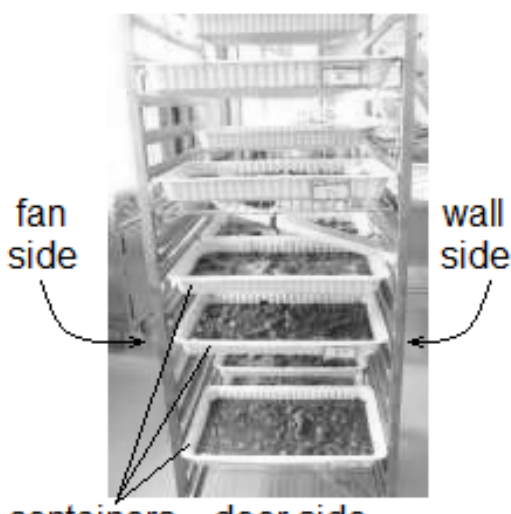

a) containers door side

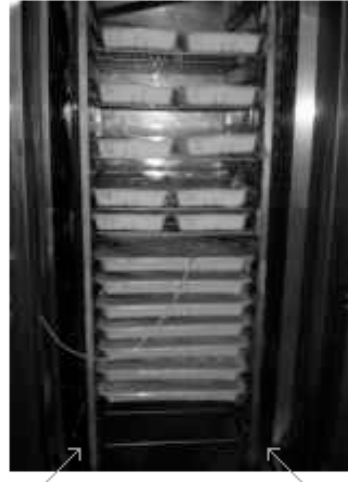

b) fan side wall side

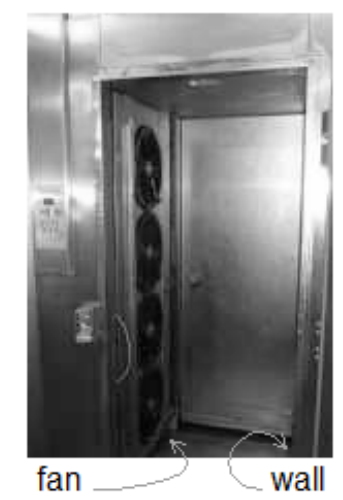

c) side side

Figure 1: Blast-cooling operation at the hospital kitchen: (a) meal containers randomly laid in the supporting trolley, (b) supporting trolley inside the blast-cooling cell, and (c) vertical line of fans inside the blast-cooling cell

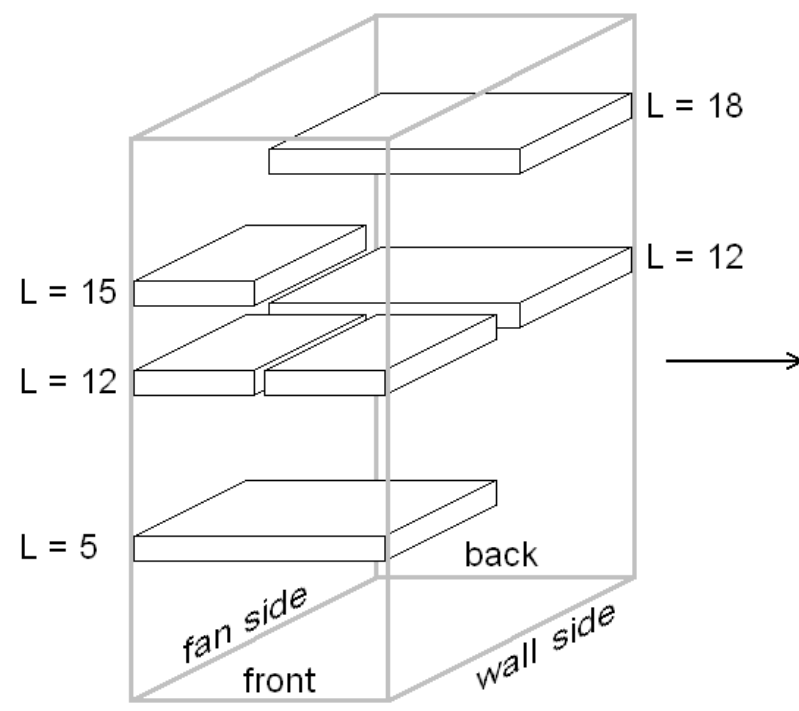

\begin{tabular}{|c|l|l|}
\hline level & front & back \\
\hline $\mathrm{L}-20$ & & \\
\hline $\mathrm{L}-19$ & & \\
\hline $\mathrm{L}-18$ & & \\
\hline $\mathrm{L}-17$ & & \\
\hline $\mathrm{L}-16$ & & \\
\hline $\mathrm{L}-15$ & & \\
\hline $\mathrm{L}-14$ & & \\
\hline $\mathrm{L}-13$ & & \\
\hline $\mathrm{L}-12$ & & \\
\hline $\mathrm{L}-11$ & & \\
\hline $\mathrm{L}-10$ & & \\
\hline $\mathrm{L}-09$ & & \\
\hline $\mathrm{L}-08$ & & \\
\hline $\mathrm{L}-07$ & & \\
\hline $\mathrm{L}-06$ & & \\
\hline $\mathrm{L}-05$ & & \\
\hline $\mathrm{L}-04$ & & \\
\hline $\mathrm{L}-03$ & & \\
\hline $\mathrm{L}-02$ & & \\
\hline $\mathrm{L}-01$ & & \\
\hline
\end{tabular}

Figure 2: Pictorial sketch of the arrangement related to a hypothetical trolley load of $N_{\text {laid }}=4.5$ containers 
a)

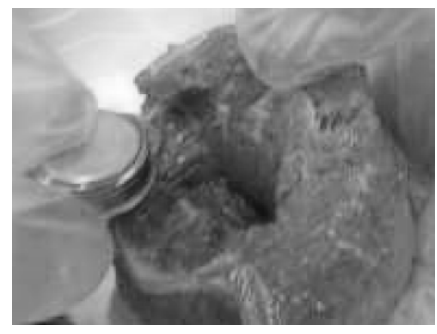

b)

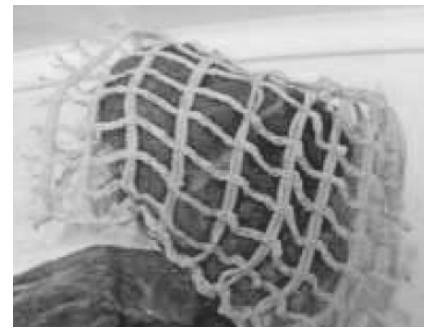

c)

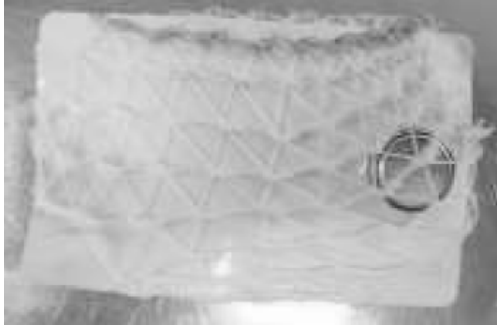

Figure 3: (a) Placement of temperature recorders in meat pieces and (b) their identification with a soft net; (c) placement and identification of recorders for sauce temperature measurements

posed to represent the arrangement in the trolley, which is shown in Fig. 2 for an invented load of $N_{\text {laid }}=3 \times 1+3 \times 0.5=4.5$ containers. In this illustrative example, containers placed at $5^{t h}$ and $18^{\text {th }}$ shelf levels are identified as L-05 front and L-18 back, respectively.

Over the investigation period, three types of beef-in-sauce meals were prepared, namely: "bœuf bourguignon", "bœuf mironton" and "goulash". Temperatures were measured through Proges-Plus small disc-shape recorders (diameter $=20 \mathrm{~mm}$, height $=6 \mathrm{~mm}$ ) and temperature-time profiles were recovered from disc memory via Thermotrack hardware and software.

Recorders were placed in meat pieces at simmer start, Fig. 3(a), and those pieces were wrapped by a soft net for recognition, Fig. 3(b). For sauce temperature measurements, recorders were supported by a small plaque and wrapped by a soft net as well, Fig. 3(c). After containers were filled up with recently-cooked meals, those identifiable meat and sauce temperature recorders were placed at the container geometric centre, which tends to be the hottest point throughout the process. It is worth noting that not all containers had recorders therein. For air temperature measurements, recorders were placed during the very short time gap between containers' top-sealing with plastic film and their placement in the trolley.

\section{Dynamic Thermal Model with Zero-Order Spatial Dependence (TM-0)}

Seeking a compromise between application versatility and realistic description, a dynamic zeroorder model (TM-0) was proposed in Rabi et al. (2012) for the blast-cooling operation described in the previous section. It relies on lumpedparameter analysis (Özışı, 1985) so that temperatures may vary with time $t$ only, i.e., no spatial dependence is allowed. This thermal model is briefly presented here for quick reference.

Let $m_{\text {food }}$ and $c_{\text {food }}$ be the mass and specific heat capacity of a catering meal within a container at a given position in the trolley. By supposing that $m_{\text {food }}$ and $c_{\text {food }}$ remain constant, an energy balance yields:

$$
\begin{array}{r}
\frac{d\left(m_{\text {food }} c_{\text {food }} T_{\text {num }}\right)}{d t}=-\dot{Q}_{\text {food } \rightarrow \text { air }} \\
\Rightarrow m_{\text {food }} c_{\text {food }} \frac{d T_{\text {num }}}{d t} \\
=-\left(\dot{Q}_{\text {food } \rightarrow \text { air }, \text { inf }}-\dot{Q}_{\text {food } \rightarrow \text { air }, \text { sup }}\right)
\end{array}
$$

where $T_{\text {num }}=T_{\text {num }}(\mathrm{t})$ is the meal temperaturetime profile to be numerically assessed where as $\dot{Q}_{\text {food } \rightarrow \text { air,sup }}$ and $\dot{Q}_{\text {food } \rightarrow \text { air,inf }}$ are heat transfer rates to cooling air flowing above and below the container. Equation (1) assumes that (i) heat is predominantly transferred across the bottom and top horizontal surfaces of the container (of equal areas $A_{\text {inf }}=A_{\text {sup }}=A$ ) and (ii) temperature $T_{\text {num }}$ refers to the meal as a whole (i.e., zero-order model with respect to spatial dependence).

In view of air flows induced in the blast-cooling 
cell, meals were assumed to ultimately lose heat by forced convection, whose comprehensive modelling is complex due to mutual interference between velocity and temperature in the fluidfluid (Kays \& Crawford, 1993). Yet, computational fluid dynamics (Norton \& DaWen, 2007) was considered beyond the modelling compromise and development strategy of Quant'HACCP Project so that heat transfer rates were linearized via a convective coefficient $h_{c}$.

No distinction was made between convective coefficients at top and bottom surfaces and, thus, the same value $h_{c, \text { inf }}=h_{c, \text { sup }}=h_{c}$ was assumed for a given container (Rabi et al., 2012). Still, coefficient $h_{c}$ was allowed to vary not only from one container to another in the trolley but also from one blast-cooling operation to another.

It is worth recalling that lumped-parameter analysis is suitable only if the resulting Biot number is sufficiently low, namely $\mathrm{Bi}<0.1$ (ÖZışıı, 1985). In line with an electrical network analogy (van der Sman, 2003), such a constraint is relaxed in TM-0 by accounting for thermal resistances between the meal core and each horizontal surface exposed to cooling air. By reasoning on the relative magnitude of such resistances (Rabi et al., 2012), one may sufficiently consider a conductive resistance for each half-length $I_{1 / 2}$ between the meal core and each horizontal edge, being $\lambda_{\text {food }}$ meal thermal conductivity. If $T_{\text {air,sup }}(t)$ and $T_{\text {air,inf }}(t)$ are the temperatures of the cooling air flowing in the vicinity of the container, Eq. 1 then becomes:

$$
\begin{aligned}
\frac{d T_{n u m}(t)}{d t} & =-\beta\left[T_{\text {num }}(t)-T_{\text {air }}(t)\right], \\
T_{\text {air }}(t) & =\frac{T_{\text {air }, \text { inf }}(t)+T_{\text {air }, \text { sup }}(t)}{2}
\end{aligned}
$$

In the previous equation, lumped parameter $\beta$ is defined as:

$$
\beta=\frac{2 A /\left(m_{\text {food }} c_{\text {food }}\right)}{1 / h_{c}+I_{1 / 2} / \lambda_{\text {food }}}
$$

while $T_{\text {air }}(t)$ is the temperature-time profile averaged from those recorded for the cooling air flowing below and above the container, as indicated in Eq. 3. One may interpret $T_{\text {air }}(t)$ as a representative temperature-time profile of the cooling air around the container. Solution of Eq. 3 requires an initial condition, namely:

$$
T_{\text {num }}(0)=T_{\text {init }}
$$

where $T_{\text {init }}$ is obtained from the temperatures recorded at operation's start-up.

\section{Thermophysical Parameters and Numerical Solution Method}

In TM-0, meals are assumed to have uniform specific heat capacity $\mathrm{c}_{\text {food }}$, thermal conductivity $\lambda_{\text {food }}$ and density $\rho_{\text {food }}$, which are assessed from meat and sauce values via a weighted-average procedure (Sepúlveda \& Barbosa-Cánovas, 2003). As discussed in Rabi et al. (2012), thermophysical properties directly or indirectly invoked in TM-0 were either taken from the literature (CEN, 1993; Zhang, Lyng, Brunton, Morgan, \& McKenna, 2004; Amos, Willix, Chadderton, \& North, 2008; Marcotte, Taherian, \& Karimi, 2008), estimated in situ or measured by means of CT-Metre (CSTB Grenoble). Table 1 shows thermophysical parameters for the numerical solution of governing equations. They were assumed to represent the catering meals studied and to remain constant during the blast-cooling operation.

For each container with meat, sauce and air temperature recordings, meal profile $T_{r e c}(t)$ was assessed in line with Rabi et al. (2012). The numerical profile $T_{\text {num }}(t)$ was evaluated in response to profile $T_{\text {air }}(t)$ by means of Eq. 3 together with a best-fitting coefficient $h_{c}$. By recalling that profiles are discrete, such an $h_{c}$ value is the one that minimises squared differences between $T_{\text {num }}(t)$ and $T_{\text {rec }}(t)$ according to:

$$
\Delta T_{a v}^{2}=\frac{1}{t_{\text {final }}} \sum_{t=0}^{t_{\text {final }}}\left[T_{\text {rec }}(t)-T_{\text {num }}(t)\right]^{2}
$$

where $t_{\text {final }}$ is blast-cooling final instant (shutdown), which varied from one operation to another. As temperatures were recorded for every minute, time $t$ behaves like a dimensionless counter in Eq. 6, being $t_{\text {final }}$ the final index. Consequently, $\Delta T_{a v}^{2}$ has the same units as $\left[T_{r e c}(t)-T_{n u m}(t)\right]^{2}$.

As stated, temperature-time profiles were 
Blast-cooling of catering meals: results from zero-order model $\mid 219$

Table 1: Thermophysical parameters for the numerical solution method

\begin{tabular}{lcc}
\hline Parameter & SI units & Value \\
\hline Horizontal area for heat transfer & $\mathrm{m}^{2}$ & $A=0.17225$ \\
Meat fractions in meals & dimensionless & mass basis $=0.640$, volume basis $=0.645$ \\
Densities & $\mathrm{kg} \mathrm{m}^{-3}$ & $\rho_{\text {meat }}=1007.1, \rho_{\text {sauce }}=1027.7, \rho_{\text {food }}=1014.4$ \\
Meal half-height in container & $\mathrm{m}$ & $I_{1 / 2}=0.015$ \\
Meal mass in container & $\mathrm{kg}$ & $m_{\text {sauce }}=\rho_{\text {food }}\left(2 I_{1 / 2}\right) A=5.242$ \\
Specific heat capacities & $\mathrm{J} \mathrm{kg}^{-1} \mathrm{~K}^{-1}$ & $C_{\text {meat }}=3030.0, C_{\text {sauce }}=4461.9, C_{\text {food }}=3545.5$ \\
Thermal conductivities & $\mathrm{W} \mathrm{m}^{-1} \mathrm{~K}^{-1}$ & $\lambda_{\text {meat }}=0.400, \lambda_{\text {sauce }}=0.648, \lambda_{\text {food }}=0.488$ \\
\hline
\end{tabular}

recorded with the least possible interference in the usual (and non-academic) modus operandi of the hospital kitchen. In principle, inherent variability could prevent one from arriving at a representative coefficient $h_{c}$ to evaluate convective heat transfers regardless of container location in the trolley. By assessing the bestfitting $h_{c}$ for a large number of meal samples, this work aimed at determining the variation range of coefficient $h_{c}$ for the blast-cooling operation taken as the case study.

Only for the particular case where air temperature $T_{\text {air }}$ is constant, one is able to deduce an analytical solution of Eq. 3 subjected to Eq. 5. This is not the case of the blast-cooling operation studied so that Eq. 3 was numerically solved. Specifically, the $4^{\text {th }}$ order Runge-Kutta method (Kreyszig \& Norminton, 1993) was implemented using MS Excel ${ }^{\circledR}$. In the same spreadsheet, the "Solver" optimization tool was used so as to determine the best-fitting coefficient $h_{c}$ minimising $\Delta T_{a v}^{2}$ in Eq. 6. Cell assessing $\Delta T_{a v}^{2}$ was defined as the target to be minimised while the cell containing $h_{c}$ value was defined as the sole adjustable one. The non-negative values option was checked while the linear model was left unchecked.

\section{Results and Discussion}

Temperatures were recorded for containers that food operators randomly placed at various positions in the trolley. From the whole set of measurements, 119 containers had meal temperatures recorded along with the temperature of the cooling air flowing nearby, thus enabling the determination of 119 best-fitting coefficients $h_{c}$. Using the pictorial sketch of Fig. 2 along with the number $N_{\text {laid }}$ of containers in the trolley, Fig. 4 shows the arrangements noted in technical visits over one year. Containers with numbers are those with temperature recorders so that the best-fitting $h_{c}$ could be determined. Those numbers are those $h_{c}$ values in SI units. Although the arrangement could not be fully registered in the first 3 technical visits, it was possible to identify the position of containers whose best-fitting $h_{c}$ could be determined. The number $N_{\text {laid }}$ of containers was not the same from one operation to another because it varied in proportion to the amount of meals cooked but $N_{\text {laid }}$ remained below $50 \%$ of the trolley's total capacity in all visits. Apart from the unique arrangement of a full load (unlikely attainable in view of the customary quantity of meals cooked), there are distinct ways to lay containers in the trolley, which was indeed the case as shown in Fig. 4.

Besides time dependence already accounted in TM-0, the number $N_{\text {laid }}$ of containers as well as their arrangements in the trolley are expected to affect the cooling performance (Barbin \& Junior, 2011). With respect to air temperatures, Fig. 5 shows profiles $T_{\text {air }}(\mathrm{t})$ concerning the lowest and highest loads, namely (a) $N_{\text {laid }}=12.0$ containers ( $4^{\text {th }}$ technical visit) and (b) $N_{\text {laid }}=$ 18.5 containers ( $6^{\text {th }}$ technical visit). Profiles follow a similar trend with cooling air temperatures reaching values as low as $-25^{\circ} \mathrm{C}$. Local peaks in profiles correspond to eventual openings of the cell door by food operators for inspection purposes. 
Not able to register arrangements in:

Technical visit \#1: $N_{\text {laid }}=14.0$

Technical visit \#2: $N_{\text {laid }}$ not noted

Technical visit \#3: $N_{\text {laid }}$ not noted

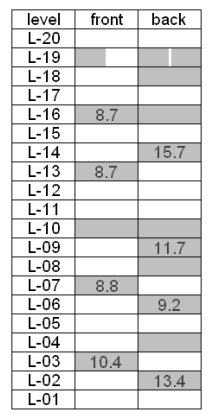

Technical visit \#8: $N_{\text {laid }}=15.5$

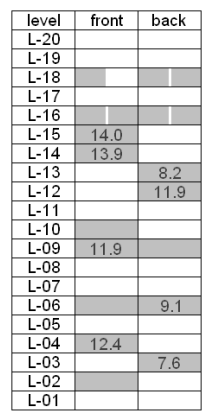

Technical visit \#13: $N_{\text {laid }}=15.5$

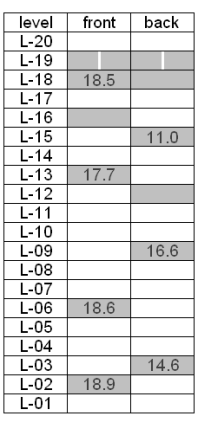

Technical visit \#4:

$N_{\text {laid }}=12.0$

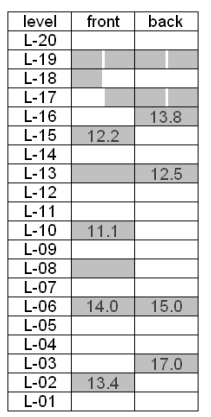

Technical visit \#9: $N_{\text {laid }}=14.0$

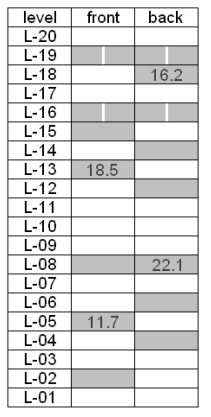

Technical visit \#14: $N_{\text {laid }}=15.0$

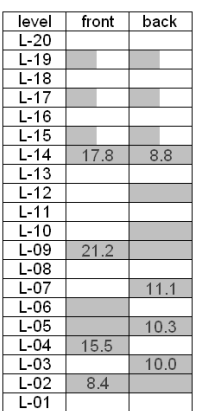

Technical visit \#5:

$N_{\text {laid }}=17.0$

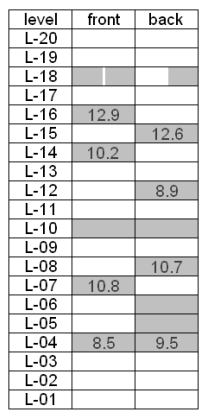

Technical visit \#10: $N_{\text {laid }}=13.5$

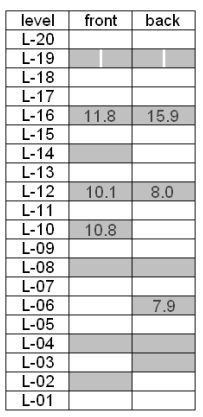

Technical visit \#15:

$N_{\text {laid }}=15.0$

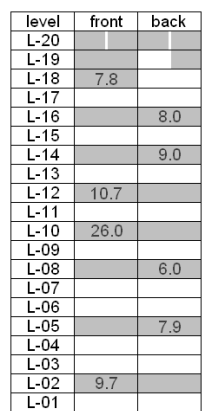

Technical visit \#6: $N_{\text {laid }}=18.5$

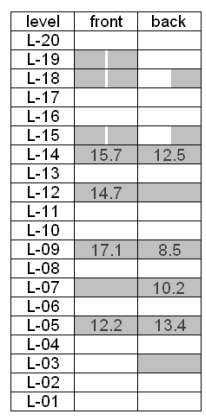

Technical visit \#11: Technical visit \#12 $N_{\text {laid }}=15.0$

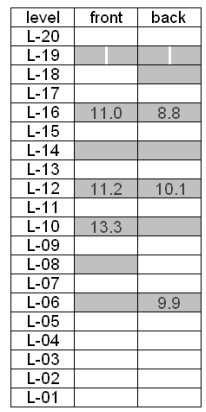

Technical visit \#16: $N_{\text {laid }}=14.0$

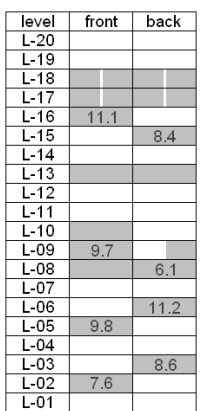

Technical visit \#7:

$N_{\text {laid }}=16.5$

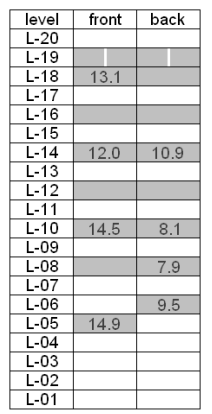

$$
N_{\text {laid }}=16.0
$$

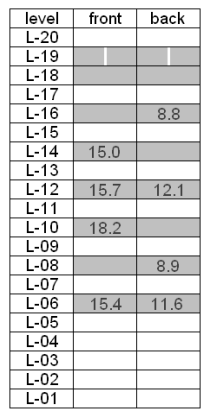

Technical visit \#17: $N_{\text {laid }}=16.0$

Figure 4: Arrangement and number $N_{\text {laid }}$ of containers in the trolley as observed in technical visits to the hospital. Numbers in the container positions are the corresponding best-fitting convective coefficient $h_{c}$ in SI units 
a)

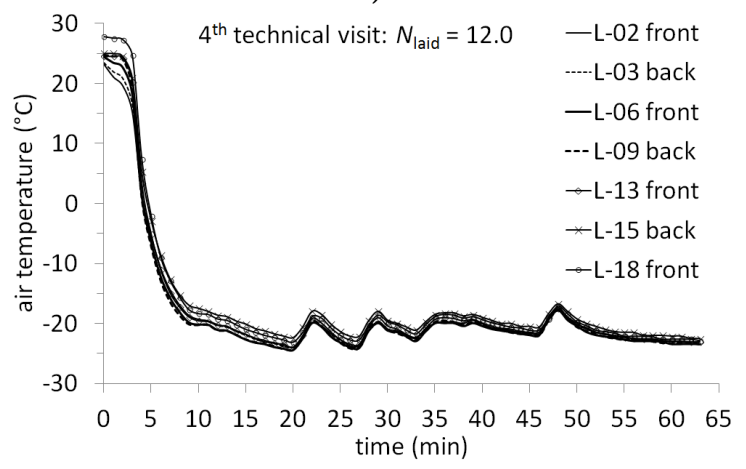

b)

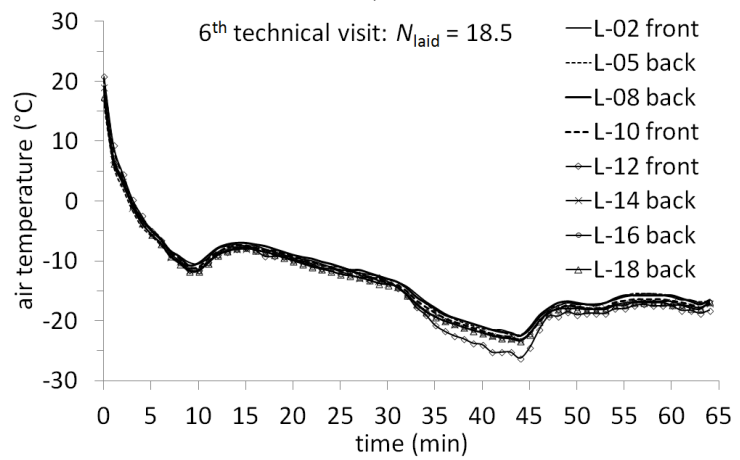

Figure 5: Air temperature-time profiles $T_{a i r}(t)$ concerning (a) the lowest and (b) the highest load observed over the investigation period

As each best-fitting coefficient $h_{c}$ can only ensure that differences between recorded and numerical temperature-time profiles are minimal, it is important to check how close $T_{\text {num }}(\mathrm{t})$ is to $T_{r e c}(\mathrm{t})$. Figure 6 compares those profiles for the worst and best objective function values, namely (a) $\Delta T_{a v}^{2}=5.85^{\circ} \mathrm{C}^{2}$ (container L-16 front, $3^{r d}$ technical visit) and (b) $\Delta T_{a v}^{2}=0.03^{\circ} \mathrm{C}^{2}$ (container L-16 back, $16^{\text {th }}$ technical visit). For completeness, corresponding air temperature-time profiles $T_{\text {air }}(t)$ are also shown in Fig. 6.

As commented, coefficient $h_{c}$ was expected to differ from one meal to another as inherent uncertainty and/or variability was transferred to it via model equations. Expressed as the number of counts and obtained via the MS Excel ${ }^{\circledR}$ built-in function "Frequency", Fig. 7 presents the distribution of all 119 best-fitting coefficients $h_{c}$. a)

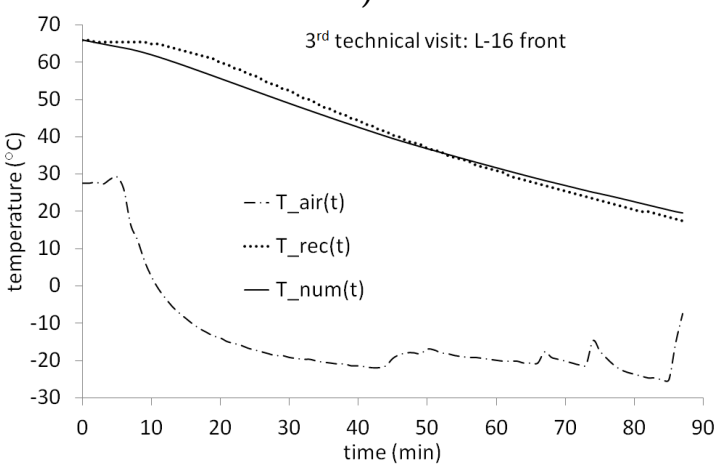

b)

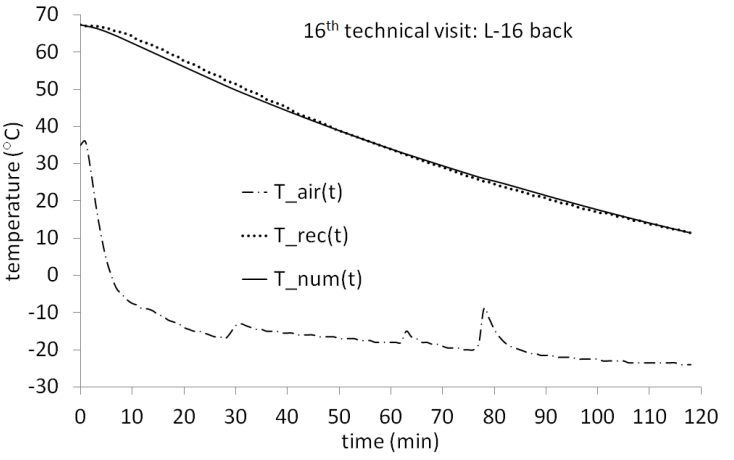

Figure 6: Recorded and numerical meal temperature-time profiles, $T_{r e c}(t)$ and $T_{\text {num }}(t)$, related to (a) the worst $\left(\Delta T_{a v}^{2} 5.85^{\circ} \mathrm{C}^{2}\right)$ and (b) the best $\left(\Delta T_{a v}^{2} 0.03^{\circ} \mathrm{C}^{2}\right)$ objective function values, together with the corresponding cooling air profile $T_{\text {air }}(t)$

The average value and standard deviation results were $h_{c}=12.0 \pm 4.1 \mathrm{~W} \mathrm{~m}^{-2} \mathrm{~K}^{-1}$.

Table 2 shows minimum, maximum and average best-fitting $h_{c}$ (together with standard deviations) as grouped by meal type or by the number $N_{\text {laid }}$ of containers in the trolley. With respect to meal type, minimum values (linked to worst cooling scenarios) are similar, $h_{c} \approx 6.0 \mathrm{~W} \mathrm{~m}^{-2}$ $\mathrm{K}^{-1}$, while the standard deviation is greater for "bœuf bourguignon".

With regard to the number $N_{\text {laid }}$ of containers, minimum $h_{c}$ values seem unrelated while average $h_{c}$ values do not seem to follow a specific trend, as shown in Fig. 8. Best-fitting coefficients $h_{c}$ can indeed be dissimilar for the same $N_{\text {laid }}$ thus ren- 
$222 \mid$ Rabi et al.

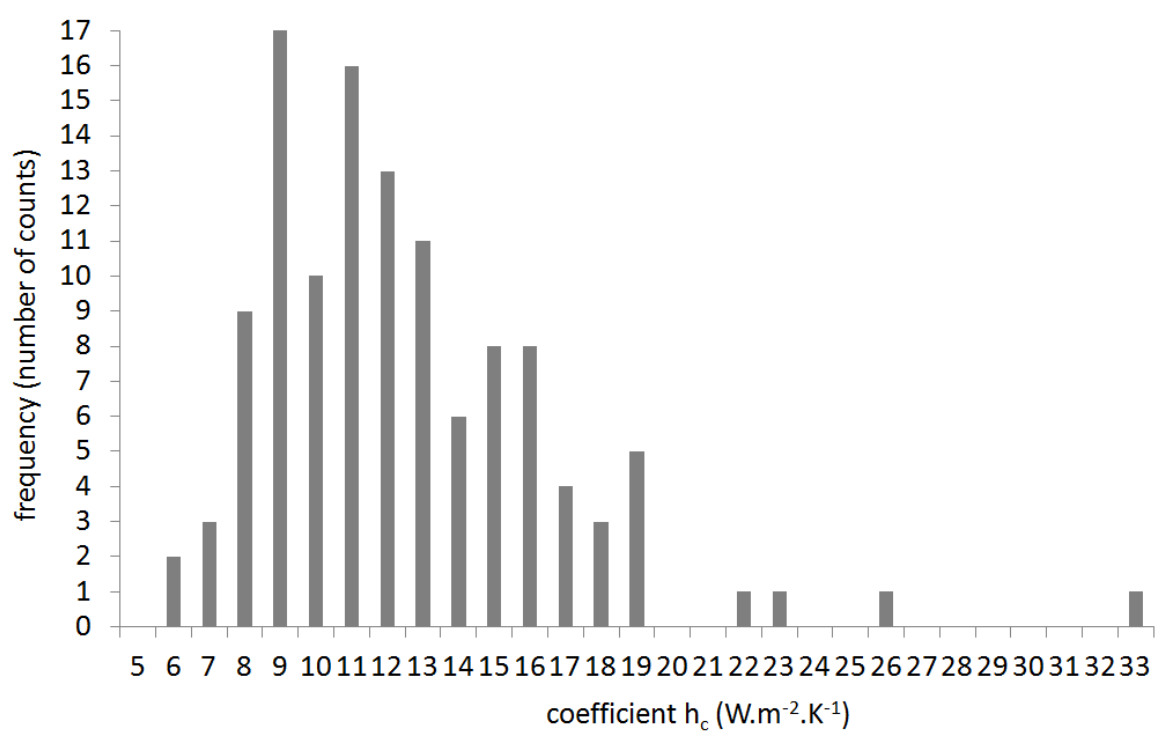

Figure 7: Distribution of all 119 best-fitting convective coefficients $h_{c}$ (obtained with the help of MS Excel $^{\circledR}$ built-in function "Frequency")

dering relatively higher standard deviations, as one may verify for $N_{\text {laid }}=18.5$ containers. Figure 9 attempts to correlate best-fitting $h_{c}$ values with the position in the trolley but no clear-cut trend can be observed.

As far as comparison with $h_{c}$ values from empirical correlations is concerned, a first issue refers to whether or not a classical geometry prevails, e.g. internal flow through a rectangular duct or external flow over a flat plate. It may even resemble a combination of these two and, as suggested in Fig. 10(a), air currents are likely to follow curved split pathways. In addition, the variability in container arrangements (Fig. 4) may complicate the evaluation of necessary parameters such as cross-sectional area, wetted perimeter and reference length. For trial calculations, let the DittusBoelter correlation be invoked, while recalling that air is heated by containers (Özışık, 1985):

$$
N u_{D}=0.023 \operatorname{Re}_{D}^{0.8} \operatorname{Pr}^{0.4}
$$

where $N u_{D}=\frac{h_{c} D_{h}}{\lambda_{\text {air }}}, R e_{D}=\frac{v_{\text {fluid }} D_{h}}{v_{\text {air }}}$ and $v_{\text {fluid }}$ is reference flow velocity, whereas air parameters are thermal conductivity $\lambda_{\text {air }}$, kinematic viscosity $v_{\text {air }}$ and Prandtl number Pr.
Nusselt number $\mathrm{Nu}_{D}$ and Reynolds number $\mathrm{Re}_{D}$ are both based on the hydraulic diameter $D_{h}$. Anemometers at the wall side of the trolley recorded air velocities around $v_{\text {fluid }} \approx 2.0 \mathrm{~m} . \mathrm{s}^{-1}$. Figure 10(b) shows a typical arrangement with two neighbouring containers leading to $D_{h}=$ $0.263 \mathrm{~m}$. Based on air properties at $-23^{\circ} \mathrm{C}(=250$ $\mathrm{K})$, for instance, Nusselt number $\mathrm{Nu}_{D}$ and coefficient $h_{c}$ then become:

$$
\begin{aligned}
& N u_{D}=(0.023)(55427)^{0.08}(0.719)^{0.4}=125.72 \\
& \Rightarrow h_{c}=\frac{(0.0224)(125.72)}{(0.263}=10.7 \mathrm{~W} \cdot \mathrm{m}^{-2} \cdot \mathrm{K}^{-1}
\end{aligned}
$$

the later being comparable to the average $h_{c}$ value already reported.

For the blast-cooling operation studied in this work, applicability of lumped-parameter analysis (i.e. zero-order modelling with respect to spatial coordinates) depends on whether the Biot number Bi results are sufficiently small (Özışı, 1985), as stated in section 3. By relying on values in Table 1 , the following convective coefficient $h_{c}$ 
Blast-cooling of catering meals: results from zero-order model $\mid 223$

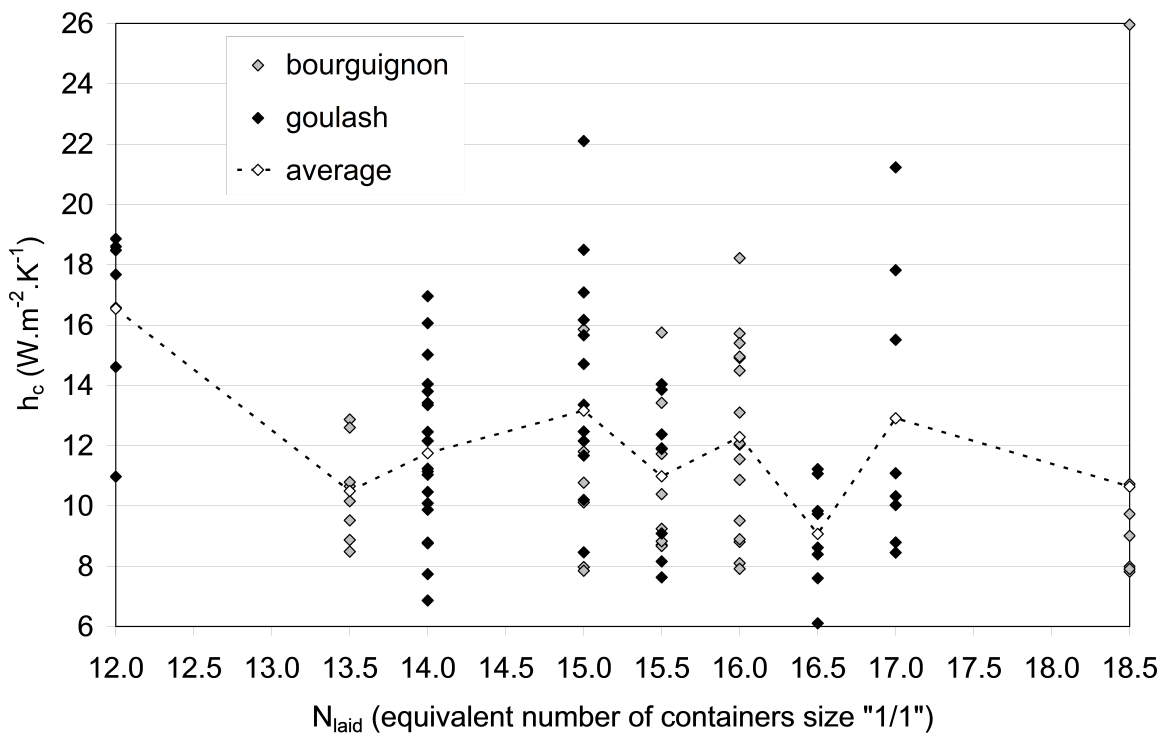

Figure 8: Best-fitting coefficients $h_{c}$ as a function of the number $N_{\text {laid }}$ of containers in the trolley (white dots refer to the corresponding average value regardless of the meal type)

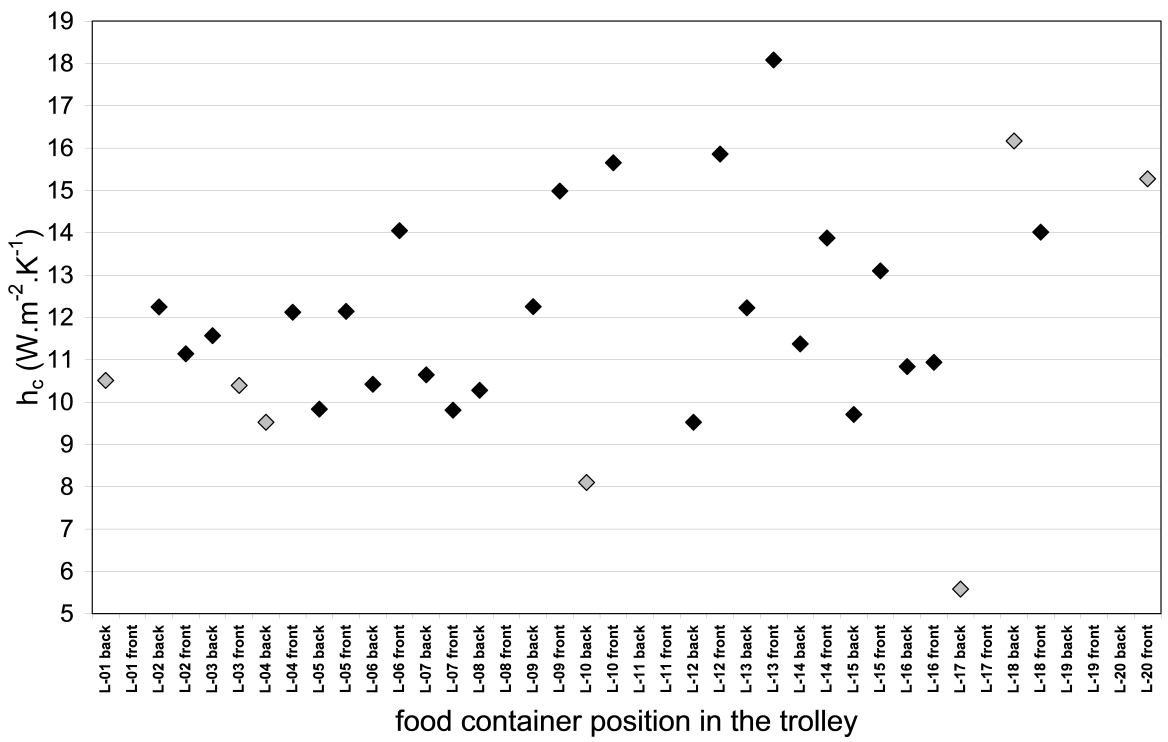

Figure 9: Best-fitting coefficients $h_{c}$ for each position in the trolley: grey dots refer to positions where only one meal temperature-time profile was available while black dots refer to positions with more than one profile 
a)

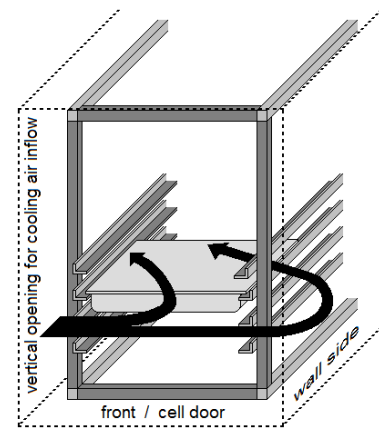

b)

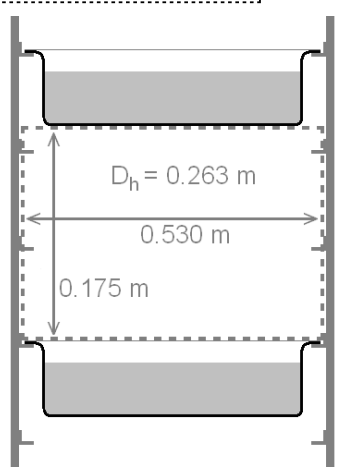

Figure 10: (a) Warmer air is aspired by 4 fans vertically lined up in one side of the cell while cooling air is blown back to the cell interior through two vertical openings, one at each side of the fans' line. (b) Typical arrangement with two neighbouring containers in a given side of the supporting trolley

should hold for $\mathrm{Bi}=0.1$ :

$$
\begin{aligned}
B i=\frac{h_{c} I_{1 / 2}}{\lambda_{\text {food }}} \Rightarrow & h_{c}=\frac{(0.01)(0.488)}{(0.015} \\
& =3.33 \mathrm{~W} \cdot \mathrm{m}^{-2} \cdot \mathrm{K}^{-1}
\end{aligned}
$$

which is slightly lower than the smallest bestfitting $h_{c}$ (worst cooling scenario).

Before jumping to the conclusion that high-order modelling with respect to spatial coordinates is strictly necessary, it is worth highlighting that the regular (and non-academic) blast-cooling operation was disturbed as little as possible. Accordingly, a balance between accuracy and process variability was attempted with reference to representative thermophysical properties and recorded profiles.

Still, as TM-0 accounts for meal thermal resistance, numerical meal temperature profiles fit well to experimental counterparts, as previously suggested in Fig. 6. In order to verify how $T_{\text {num }}(\mathrm{t})$ closely follows $T_{\text {rec }}(\mathrm{t})$ for all 119 meal samples studied, $\mathrm{R}^{2}$ values were assessed through the MS Excel ${ }^{\circledR}$ built-in function "RSQ" by assuming a linear regression based on those two profiles. Encouraging results are shown in Fig. 11 for all 119 best-fitting coefficients $h_{c}$.

Though distinct convective coefficients for bottom and top surfaces (hc,inf $\neq$ hc,sup) could bring an extra degree of freedom, the best-fitting procedure based on Eq. (6) would become more complex and beyond the scope of this work. Process modelling should rely on governing equations, correlations and parameters with complexity balancing between the following issues:

- Variability of parameters that characterize either food products (e.g. composition, homogeneity and amount in containers) or process (e.g. equipment operation, prevailing ambient conditions and arrangement inside the equipment);

- Accuracy of input data (e.g. process parameters) and desired outputs (e.g. food safety and/or performance objectives, process optimization and/or re-engineering).

As claimed in de Souza-Santos (2004), sophistication is not a guarantee for model quality and it should go only to the point where key variables can be compared with available experimental data. Moreover, complex models are prone to require information that cannot be straightforwardly measured in a non-academic environment like the hospital kitchen investigated. It is worth recalling that the Quant'HACCP Project seeks unsophisticated approaches that may render general recommendations to operators, whilst being easily adaptable to similar case studies. Bearing in mind that catering chains may follow distinct processes, care should be exercised so as to prevent over-complicating or over-simplifying a model for use. Such is a critical task as relatively simple models may satisfactorily work for predictive microbiology purposes (Buchanan, Whiting, \& Damert, 1997). 
Blast-cooling of catering meals: results from zero-order model $\mid 225$

Table 2: Maximum, minimum and average best-fitting coefficients $h_{c}$ (together with standard deviations)

\begin{tabular}{|c|c|c|c|c|c|}
\hline $\begin{array}{l}\text { Best-fitting coefficient } \\
h_{c} \text { as grouped by: }\end{array}$ & $\begin{array}{c}\text { Number of } \\
\text { profiles }\end{array}$ & $\begin{array}{l}\text { Minimum } h_{c} \\
\left(\mathbf{W} \mathbf{m}^{-2} \mathbf{K}^{-1}\right)\end{array}$ & $\begin{array}{l}\text { Maximum } h_{c} \\
\left(\mathbf{W} \mathbf{m}^{-2} \mathbf{K}^{-1}\right)\end{array}$ & $\begin{array}{c}\text { Average } \boldsymbol{h}_{c} \\
\left(\mathbf{W} \mathbf{m}^{-2} \mathbf{K}^{-1}\right)\end{array}$ & $\begin{array}{l}\text { Standard } \\
\text { deviation }\end{array}$ \\
\hline Goulash & 62 & 6.1 & 22.1 & 12.5 & 3.7 \\
\hline Bøuf bourguignon & 53 & 5.6 & 32.7 & 11.7 & 4.5 \\
\hline Bœuf mironton & 4 & 6.2 & 11.1 & 8.8 & 2.1 \\
\hline$N_{\text {laid }}=12.0$ & 7 & 11.0 & 18.9 & 16.5 & 2.9 \\
\hline$N_{\text {laid }}=13.5$ & 8 & 8.5 & 12.9 & 10.5 & 1.6 \\
\hline$N_{\text {laid }}=14.0$ & 19 & 6.9 & 17.0 & 11.7 & 2.8 \\
\hline$N_{\text {laid }}=15.0$ & 18 & 7.9 & 22.1 & 13.2 & 3.9 \\
\hline$N_{\text {laid }}=15.5$ & 16 & 7.6 & 15.7 & 11.0 & 2.5 \\
\hline$N_{\text {laid }}=16.0$ & 16 & 7.9 & 18.2 & 12.3 & 3.1 \\
\hline$N_{\text {laid }}=16.5$ & 8 & 6.1 & 11.2 & 9.1 & 1.7 \\
\hline$\stackrel{0}{\square} \quad N_{\text {laid }}=17.0$ & 8 & 8.4 & 21.2 & 12.9 & 4.7 \\
\hline 艼 $\quad N_{\text {laid }}=18.5$ & 8 & 6.0 & 26.0 & 10.6 & 6.4 \\
\hline All beef-in-sauce meals & 119 & 5.6 & 32.7 & 12.0 & 4.1 \\
\hline
\end{tabular}

${ }^{a}$ The number $N_{\text {laid }}$ of food containers in the trolley could not be observed in one blast-cooling operation for "bœuf bourguignon" and in one blast-cooling operation for "bœuf mironton", as indicated in Fig. 4

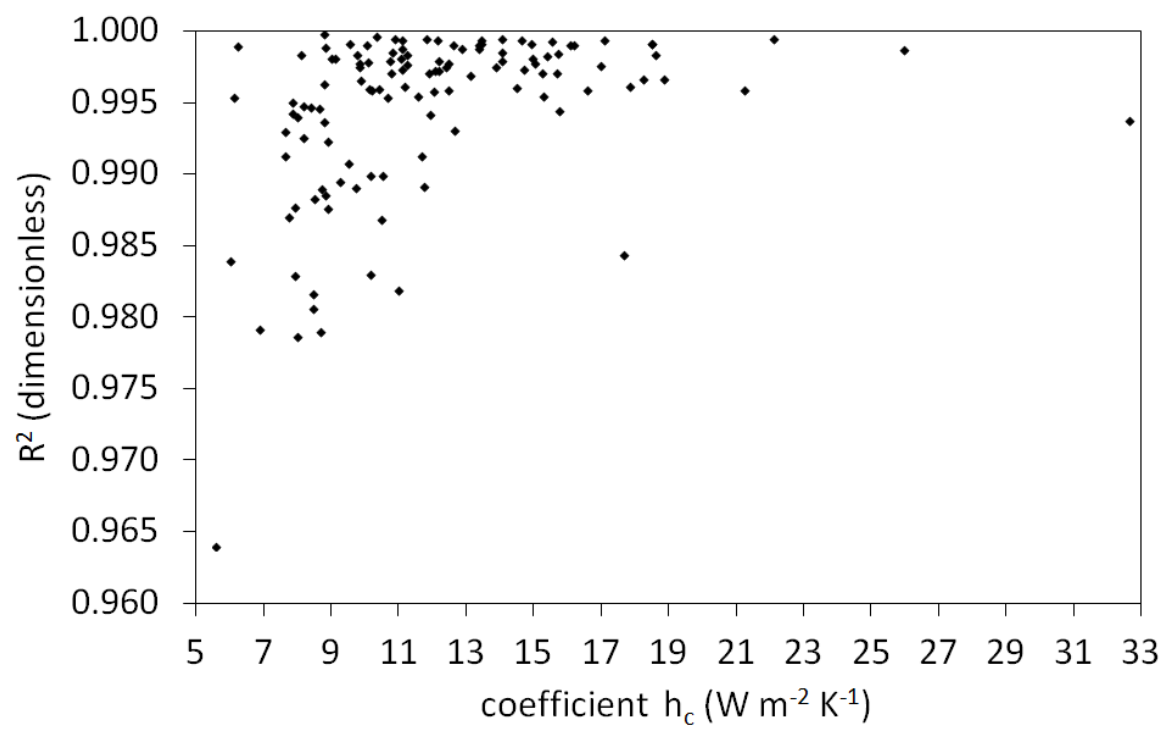

Figure 11: $\mathrm{R}^{2}$ values from the linear regression of numerical profiles $T_{\text {num }}(t)$ against the counterpart recorded $T_{\text {rec }}(t)$ for all best-fitting coefficients $h_{c}$ as calculated via MS Excel ${ }^{\circledR}$ built-in function "RSQ". 


\section{Conclusions}

It is believed that inherent variability and uncertainties were transferred to the coefficient $h_{c}$ so that the distribution of related best-fitting values may have been affected by non-uniformities attributable (but not restricted) to meal composition, meal quantity inside containers, position of temperature recorders with respect to meal core, number of containers placed in the supporting trolley, and their layout therein. In view of non-academic environments (as in the hospital kitchen studied), zero-order thermal model with respect to spatial dependence (TM-0) proved to be a suitable approach. Despite the corresponding Biot number being slightly above 0.1 , recorded and numerical meal temperature-time profiles correlated very well for several bestfitting coefficients $h_{c}$. TM-0 was implemented in MS Excel ${ }^{\circledR}$, enabling its built-in Solver tool to be successfully combined with the $4^{\text {th }}$ order Runge-Kutta method. As this work belongs to a research project which aims at general recommendations for operators during food thermal processing, use of widespread software like MS Excel $^{\circledR}$ is definitely of interest.

\section{Acknowledgements}

Authors thank ANR (Agence Nationale de la Recherche, France) for the financial support throughout this research project.

\section{References}

Almonacid, S., Simpson, R., \& Teixeira, A. (2007). Heat transfer models for predicting salmonella enteriddis in shell eggs through supply chain distribution. Journal of Food Science, 72(9), E508-E517. doi:10.1111/j. 1750-3841.2007.00528.x

Amezquita, A., Weller, C. L., Wang, L., Thippareddi, H., \& Burson, D. E. (2005). Development of an integrated model for heat transfer and dynamic growth of clostridium perfringens during the cooling of cooked, boneless ham. International Journal of Food Microbiology, 101 (2), 123-144. doi:10. 1016/j.ijfoodmicro.2004.10.041
Amos, N. D., Willix, J., Chadderton, T., \& North, M. F. (2008). A compilation of correlation parameters for predicting the enthalpy and thermal conductivity of solid foods within the temperature range of $40{ }^{\mathrm{o}} \mathrm{C}$ to $+40{ }^{\mathrm{O}} \mathrm{C}$. International Journal of Refrigeration-revue Internationale du Froid, 31(7), 1293-1298. doi:10.1016/ j.ijrefrig.2008.01.011

Barbin, D. F. \& Junior, V. S. (2011). Comparison of the effects of air flow and product arrangement on freezing process by convective heat transfer coefficient measurement. Heat Transfer e Theoretical Analysis, Experimental Investigations and Industrial Systems, ISBN, 978-953. Retrieved from http://www.intechopen.com/books/heattransfer- theoreticalanalysis- experimentalinvestigations - and - industrial - systems / comparison-of-the-effects-of-air-flow-andproductarrangement- on- freezing- processby-convective-heat

Bellara, S. R., McFarlane, C. M., Thomas, C. R., \& Fryer, P. J. (2000). The growth of escherichia coli in a food simulant during conduction cooling: combining engineering and microbiological modelling. Chemical Engineering Science, 55(24), 6085-6095. doi:10. 1016/S0009-2509(00)00178-0

Buchanan, R. L., Whiting, R. C., \& Damert, W. C. (1997). When is simple good enough: a comparison of the gompertz, baranyi, and three-phase linear models for fitting bacterial growth curves. Food Microbiology, 14(4), 313-326. 2nd International Conference on Predictive Microbiology, Hobart, Australia, Feb 18-22, 1996. doi:10.1006/ fmic.1997.0125

CEN. (1993). - Comité Européen de Normalisation (European Committee for Standardization). European standard EN 631-1: Materials and articles in contact with foodstuffs - Catering containers - Part 1: Dimensions of containers. Brussels, Belgium.

Corradini, M. G., Amezquita, A., Normand, M. D., \& Peleg, M. (2006). Modeling and predicting non-isothermal microbial growth using general purpose software. International Journal of Food Microbiol- 
Blast-cooling of catering meals: results from zero-order model $\mid 227$

ogy, 106(2), 223-228. doi:10 . 1016 / j . ijfoodmicro.2005.06.014

Crouch, E. \& Golden, N. (2005). A risk assessment for clostridium perfringens in readyto-eat and partially cooked meat and poultry products. USDA, Food Safety Inspection Service. Retrieved from http://www. fsis . usda . gov / PDF / CPerfringens_Risk_ Assess_Sep2005.pdf

de Jong, A. E. I., Beumer, R. R., \& Zwietering, M. H. (2005). Modeling growth of clostridium perfringens in pea soup during cooling. Risk Analysis, 25(1), 61-73. doi:10.1111/j. 0272-4332.2005.00567.x

de Souza-Santos, M. L. (2004). Solid fuels combustion and gasification: modeling, simulation, and equipment operations. CRC Press.

Doyle, M. E. (2002). Survival and growth of clostridium perfringens during the cooling step of thermal processing of meat products: a review of the scientific literature. Food Research Institute, University of Wisconsin-Madison.

Huang, L. H. (2003). Dynamic computer simulation of clostridium perfringens growth in cooked ground beef. International Journal of Food Microbiology, 87(3), 217-227. doi:10.1016/S0168-1605(03)00065-5

Jaloustre, S., Cornu, M., Morelli, E., Noel, V., \& Delignette-Muller, M. L. (2011). Bayesian modeling of clostridium perfringens growth in beef-in-sauce products. Food Microbiology, 28(2, SI), 311-320. doi:10.1016/j.fm. 2010.04.002

Juneja, V. K. \& Marks, H. M. (2002). Predictive model for growth of clostridium perfringens during cooling of cooked cured chickens. Food Microbiology, 19(4), 313-327. doi:10. 1006/yfmic.486

Kalinowski, R. M., Tompkin, R. B., Bodnaruk, P. W., \& Pruett, W. P. (2003). Impact of cooking, cooling, and subsequent refrigeration on the growth or survival of clostridium perfringens in cooked meat and poultry products. Journal of Food Protection, $66(7), 1227-1232$.

Kays, W. M. \& Crawford, M. E. (1993). In convective heat mass transfer ( ${ }^{\text {rd }}$, Ed.). ISBN-10: 0071125167. New York: McGraw-
Hill Education (ISE Editions); International 2 Revised ed edition.

Kreyszig, E. \& Norminton, E. J. (1993). Maple computer manual for advanced engineering mathematics. John Wiley \& Sons, Inc.

Marcotte, M., Taherian, A. R., \& Karimi, Y. (2008). Thermophysical properties of processed meat and poultry products. Journal of Food Engineering, 88(3), 315-322. doi:10.1016/j.jfoodeng.2008.02.016

Norton, T. \& Da-Wen, S. (2007). An overview of CFD applications in the food industry. In D.-W. Sun (Ed.), Computational fluid dynamics in food processing (contemporary food engineering) (pp. 1-41). ISBN10: 0849392861. Boca Raton: CRC Press.

Özışık, M. N. (1985). Heat transfer: a basic approach. New York: McGraw-Hill.

Rabi, J. A., Trezzani-Harbelot, I., Morelli, E., \& Guilpart, J. (2012). Catering meals under blast-cooling: comparison between zero and first-order modeling with respect to spatial dependence of temperature. International Review of Mechanical Engineering, $6(2), 218-227$.

Sepúlveda, D. \& Barbosa-Cánovas, G. (2003). Heat transfer in food products. Transport phenomena in food processing.

Steele, F. M. \& Wright, K. H. (2001). Cooling rate effect on outgrowth of clostridium perfringens in cooked, ready-to-eat turkey breast roasts. Poultry Science, 80(6), 813816.

van der Sman, R. G. M. (2003). Simple model for estimating heat and mass transfer in regular-shaped foods. Journal of Food Engineering, 60(4), 383-390. doi:10.1016/ S0260-8774(03)00061-X

Zhang, L., Lyng, J. G., Brunton, N., Morgan, D., \& McKenna, B. (2004). Dielectric and thermophysical properties of meat batters over a temperature range of $5-85^{\circ} \mathrm{C}$. Meat Science, 68(2), 173-184. 